\title{
Seckel syndrome
}

\author{
INSERM
}

\section{Source}

INSERM. (1999). Orphanet: an online rare disease and orphan drug data base. Seckel syndrome. ORPHA:808

Seckel syndrome is a type of microcephalic primordial dwarfism that is characterized by a proportionate dwarfism of prenatal onset, a severe microcephaly, a typical dysmorphic face (bird-like), and mild to severe intellectual disability. 